\title{
Delayed pneumothorax after transbronchial lung biopsy
}

\author{
H LEVY, J M KALlENBACH, C FELDMAN, P PINCUS, M HURWITZ \\ From the Department of Respiratory Medicine, University of the Witwatersrand, Johannesburg, South Africa
}

The complication and mortality rate associated with fibreoptic bronchoscopy and transbronchial lung biopsy are low. ${ }^{12}$ Pneumothorax has been reported to occur after about $5 \%$ of transbronchial lung biopsies and is the most common complication of the procedure.$^{3-5}$ Many extensive reviews of fibreoptic bronchoscopy with transbronchial biopsy, however, make no mention of the occurrence of delayed pneumothorax after the procedure. ${ }^{1-7}$ We report two patients who suffered delayed pneumothoraces after transbronchial lung biopsies.

\section{Case reports}

\section{Case 1}

A 15 year old recipient of a renal transplant was admitted to hospital with pneumonia suspected to be due to Pneumocystis carinii. She was being treated with prednisone and azathioprine. Examination showed her to be confused, cyanosed, and febrile, with diffuse crepitations audible. The chest radiograph showed a bilateral infiltrate, more noticeable on the left.

Multiple transbronchial lung biopsies of the left lung were performed through a fibreoptic bronchoscope with fluoroscopic guidance under general anaesthesia with muscle relaxants. Examination of the biopsy specimens showed the alveolar spaces to contain a granular exudate with cysts of Pneumocystis carinii. Treatment was started with intravenous sulphamethoxazole $800 \mathrm{mg}$ and trimethoprim $160 \mathrm{mg}$ administered eight hourly.

Fluoroscopy of the chest and an erect expiratory chest radiograph, performed immediately after the procedure, and the chest radiograph obtained the following morning showed no evidence of pneumothorax. Thirty six hours after the biopsy the patient became acutely distressed. The chest radiograph showed a large left sided pneumothorax. Despite the insertion of an intercostal drain her condition deteriorated and mechanical ventilation was instituted.

After a complicated 18 day course extubation was possible. The pulmonary infiltrate progressively cleared radiologically and the patient was discharged from hospital.

\section{Case 2}

A 28 year old nursing sister was admitted to hospital with a three month history of weight loss and dry cough. Chest radiographs showed progressive consolidation of the posterior segment of the left upper lobe. Because the sputum was persistently negative for acid fast bacilli and other bacte-

Address for reprint requests: Dr Howard Levy, Department of Medicine, Johannesburg Hospital, Private Bag X39, Johannesburg 2000, South Africa.

Accepted 13 January 1986 rial pathogens and the response to skin testing with PPD (5 TU) was negative, fibreoptic bronchoscopy and transbronchial lung biopsy were performed, with fluoroscopy. At her request the procedure was done under general anaesthesia and muscle relaxants were used.

Examination of biopsy specimens from the left upper lobe showed granulomas with Langhans giant cells. Microscopic examination of bronchial washings failed to detect acid fast bacilli but culture yielded colonies of Mycobacterium tuberculosis.

Fluoroscopy of the chest and an erect expiratory chest radiograph performed immediately after the procedure showed no evidence of a pneumothorax. Antituberculous treatment was started and the patient was discharged from hospital 48 hours after the biopsy.

Five days later she was seen at the local tuberculosis clinic, where she gave a history of left sided chest pain that began the day after discharge. The chest radiograph showed a large left sided pneumothorax. A chest drain was inserted, with immediate re-expansion of the lung, and removed three days later. The patient responded to antituberculous treatment.

\section{Discussion}

The morbidity and mortality associated with fibreoptic bronchoscopy with or without transbronchial lung biopsy is low. ${ }^{12}$ A recent United Kingdom survey reported a 2.7\% complication rate when transbronchial biopsy was performed. ${ }^{2}$ The most common complication of transbronchial lung biopsy is pneumothorax, which has been reported in three large studies to occur in $4-5.5 \%$ of cases. ${ }^{3-5}$ Pneumothorax is easily diagnosed by fluoroscopy and by taking an erect expiratory chest radiograph at the end of the procedure. $^{6}$

The reason for the delayed presentation of the pneumothoraces in our patients is uncertain. Clearly the use of the general anaesthesia would have masked the occurrence of the pain, which occurs so frequently at the time a pneumothorax is caused. The presence of the complication was, however, carefully excluded in both cases immediately after the procedure and after 24 hours in case 1 . In both subjects muscle relaxants were used, necessitating mechanical ventilation-which would itself be expected to result in rapid increase in the size of a pneumothorax. We speculate that a defect in the visceral pleura may have occurred and persisted but that it was protected by the formation of blood clot in the bronchi proximal to it. Pneumothorax could have occurred after fibrinolysis.

While tuberculosis is a known cause of pneumothorax, the rapid resolution with tube drainage in a patient with relatively stable disease leads us to believe that the pneumothorax was due to the biopsy. Pneumocystis carinii 
pneumonia is rarely associated with spontaneous pneumothorax. ${ }^{8}$ Clearly, however, we cannot be certain that the pneumothorax was not caused by the underlying disease process in our second case.

The safety of fibreoptic bronchoscopy, when performed as an outpatient procedure in carefully selected patients, has been clearly documented. ${ }^{7}$ Hospital admission of patients having transbronchial biopsies is, however, recommended. ${ }^{7}$ We agree with this and suggest that all patients should be assessed for the presence of delayed pneumothorax just before discharge from hospital. Patients should in addition be informed of the possibility of this complication and advised to seek medical assistance early in the event of symptoms that suggest its occurrence.

\section{References}

1 Fulkerson WJ. Current concepts: fiberoptic bronchoscopy. $N$ Engl J Med 1984;311:511-5.
2 Arnold AG, Belfield PW, Myers MF, et al. Postal survey of medical bronchoscopies in the United Kingdom-1: Deaths and complications [abstract]. Thorax 1984;39:219-20.

3 Hanson RR, Zavala DC, Rhodes ML, et al. Transbronchial biopsy via flexible fiberoptic bronchoscope: results in 164 patients. Am Rev Respir Dis 1976;114:67-72.

4 Pereira W Jr, Kovnat DM, Snider GL. A prospective cooperative study of complications following flexible fiberoptic bronchoscopy. Chest 1978;73:813-6.

5 Herf SM, Suratt PM, Arora NS. Deaths and complications associated with transbronchial lung biopsy. Am Rev Respir Dis 1977;115:708-11.

6 Anonymous. Hazards of fiberoptic bronchoscopy. $\mathrm{Br} \mathrm{Med} \mathrm{J}$ 1979;i:212-3

7 Ackart RS, Foreman DR, Klayton RJ, et al. Fiberoptic bronchoscopy in outpatient facilities, 1982. Arch Intern Med 1983;143:30-1.

8 Doppmann JL, Geelhoed GW, De Vita VT. Atypical radiographic features in Pneumocystis carinii pneumonia. Radiology 1975;114:39-44.

\section{Book notices}

Colour Atlas of Pulmonary Cytopathology. JA Young. (Pp 148; £55.) Oxford: Harvey Miller, 1985.

This book is the latest of a series of colour atlases currently being produced by the Oxford University Press under the general editorship of Professor RC Curran. It consists of 12 chapters, dealing with the cytology of non-neoplastic and neoplastic pulmonary disease. In the first three chapters there are illustrations of the normal constituents of sputum, lavage, needle, and brush biopsy specimens, and the changes induced by inflammation, irradiation, and drug treatment. Specific fungal infections, viral diseases, and parasitic infestations are also covered, as well as asthma and rheumatoid lesions. The cytology of primary and secondary carcinomas, carcinoid tumour lymphomas, and mesothelioma is described in the ensuing sections. The final chapter is devoted to contaminants in the sputum, including food debris, Candida, oral bacteria, and Alternaria among others. Each chapter starts with a brief but comprehensive summary of the pathological aspects, followed by a list of references. There is a more general bibliography at the end of the book. The illustrations, all of which are in colour, are of a high standard, and the text is informative and concise. Dr Young clearly has extensive experience of pulmonary cytology, and is fully aware of the pitfalls and difficulties. She has produced an outstanding bench book which will find a place in every laboratory dealing with cytological material from the respiratory tract. I cannot recommend it too highly.

CWB

Lecture Notes on Respiratory Disease. 3rd ed. RAL Brewis. (Pp 390; £8.50.) Oxford: Blackwell Scientific Publications, 1985. (0-632-01412-1.)

I have recommended this book to medical students, nurses, and technicians ever since it was first produced, because it is lucidly written and elegantly illustrated by the author. The third edition contains 78 more pages, as a result of larger print, more extended essays on some important topics, and two new chapters (on cystic fibrosis and defences of the lung). The chapters on pulmonary function and asthma are now outstandingly good. Very few recent advances have been omitted. The value of computed tomography is perhaps understated, and the detection of respiratory muscle weakness merits a mention. A better account of acute and chronic respiratory failure would be helpful and the section on the pathology and epidemiology of chronic airflow obstruction needs updating. This book imparts a clear idea of what it is like to suffer from the disorders described and of how these may be treated; I think it is the most successful of its size.-GL

Cystic Fibrosis: Manual of Diagnosis and Management. 2nd ed. MC Goodchild, JA Dodge. (Pp 212; £9.50 softback.) London: Baillière Tindall, 1985.

The first edition of this book, prepared 10 years ago by Charlotte Anderson and Mary Goodchild, was not merely a lucid short monograph on cystic fibrosis. It was an outstanding example of a book that is equally valuable as a source of information to all groups who come into contact with the disease, whether they are doctors, nurses, physiotherapists, dieticians - or indeed patients or their relatives. The second edition is a little longer, goes into rather more detail, and is slightly freer with medical terminology but it seems to have been adapted admirably for today's needs and should prove just as effective as the first edition. The book is full of uncomplicated accurate description, undramatic interpretation, and practical commonsense. A particular strength is the way in which different patterns of management are considered in turn and the aims and uncertainties discussed. Patients and relatives reading these sections are likely to come away with some understanding of the nature of medical controversy and may feel less threatened by what was previously perceived as worryingly contradictory advice. The second edition has many more references than the first and also has a valuable chapter that reviews research into basic mechanisms. As before, the function of the book as a manual is assisted by the inclusion of tables and lists containing such things as the composition and dosage of drugs, useful addresses, and lists of publications of the Cystic Fibrosis Trust. The specialist and the novice can both get a great deal from this book.

RALB 